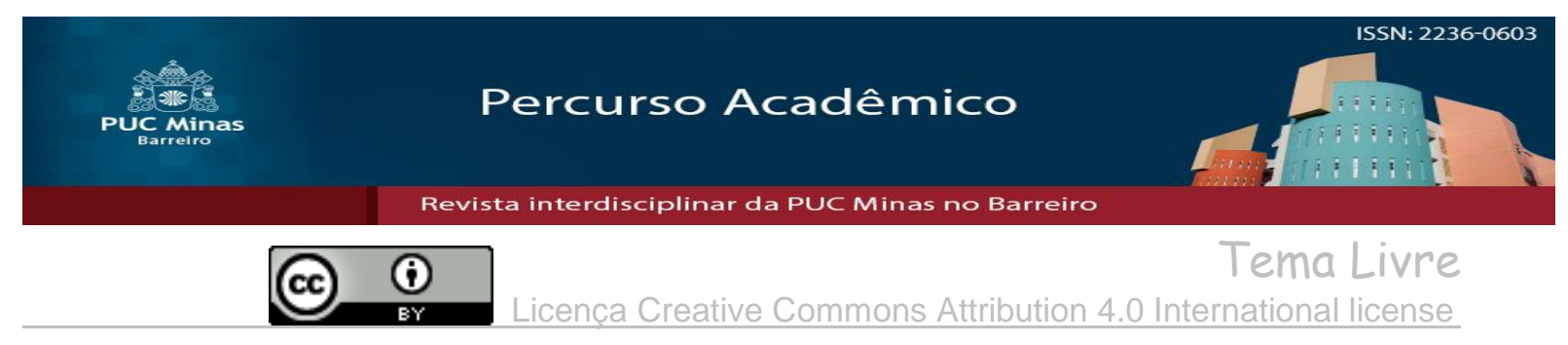

\title{
A responsabilidade civil objetiva e o dano moral presumido em decorrência do tratamento indevido de dados
}

\author{
Objective civil responsibility and presumed moral damage due to undue data \\ processing
}

\begin{abstract}
João Victor Gontijo Cardoso ${ }^{1}$
RESUMO

A sociedade da informação alterou incisivamente a forma das pessoas se relacionarem, influenciada diretamente pelo advento da Internet. O referido ambiente é responsável por armazenar inúmeras informações dos usuários, já que é nele que as pessoas se conectam e passam a maior parte do tempo. Nesse contexto, com a Lei Geral de Proteção de Dados, a ciência jurídica começa a adentrar neste fresco terreno tecnológico a fim de tutelar os informes pessoais dos sujeitos de direito, principalmente a privacidade, minimizando sua vulnerabilidade perante os agentes econômicos. Portanto, neste cenário, é imprescindível que o instituto da responsabilidade civil esteja bem delineado quando se fala em tratamento indevido de dados, nessa ambiência surge duas problemáticas, quais sejam, afere-se a culpa do tratador de dados quando há a violação a privacidade ou não, segundamente o dano moral causado pelo tratamento indevido dos dados será em presumido ou não. Diante disso, com base no método dedutivo, utilizando-se de casos concretos e a base da pesquisa bibliográfica e jurisprudencial busca-se demonstrar que os dados compõem um direito fundamental, ademais, foi realizado um recorte epistemológico da responsabilidade civil em razão do tratamento indevido dos dados, para que com o método hermenêutico-jurídico fosse possível afirmar que havendo a violação de direitos fundamentais, especialmente a privacidade acarretará o dano moral in re ipsa e a responsabilidade será objetiva, dispensando a culpa. Por fim, com base no método jurídico propositivo espera-se com este trabalho uma contribuição acadêmica, tendo em vista que os resultados alcançados foram satisfativos, ao passo que foi possível afirmar que havendo o tratamento indevido dos dados, o dano moral causado ao titular é presumido, uma vez que viola direitos fundamentais e da personalidade e a responsabilidade será objetiva, com base na teoria do risco proveito e criado.
\end{abstract}

Palavras-Chave: Responsabilidade Civil Objetiva. Tratamento de Dados. Dano Moral Presumido.

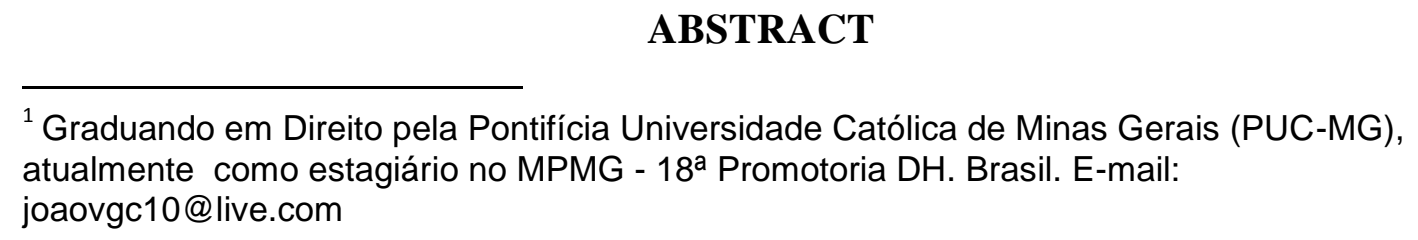

ABSTRACT

${ }^{1}$ Graduando em Direito pela Pontifícia Universidade Católica de Minas Gerais (PUC-MG), atualmente como estagiário no MPMG - 18ª Promotoria DH. Brasil. E-mail: joaovgc10@live.com 
The information society has dramatically changed the way people relate, influenced directly by the advent of the Internet. This environment is responsible for storing a lot of information from users, as this is where people connect and spend most of their time. In this context, with the General Data Protection Law, legal science begins to enter this new technological terrain in order to protect the personal information of legal subjects, especially privacy, minimizing their vulnerability to economic agents. Therefore, in this scenario, it is essential that the civil liability institute is well defined when it comes to improper data processing. In this environment, two problems arise, namely, the fault of the data controller when there is or is not a breach of privacy, on the other hand, the moral damage caused by the improper treatment of the data will be presumed or not. Therefore, based on the argumentative method, the bibliographic and jurisprudential research base seeks to demonstrate that the data constitute a fundamental right, in addition, an epistemological cut of civil liability was made due to the improper treatment of the data, so that with the method hermeneutic-legal it was possible to affirm that if there is a violation of fundamental rights, especially privacy will cause moral damage in re ipsa and the responsibility will be objective, example of guilt. Finally, based on the propositional legal method, this work is expected to make an academic contribution, considering that the results achieved were satisfactory, although it is possible to state that in case of improper treatment of the data, the moral damage caused to the presumed become holder, considering that it violates fundamental and personality rights and the responsibility will be objective, based on the theory of advantage and risk created.

Keywords: Objective Civil Responsibility. Data Processing. Presumed moral damage.

\section{INTRODUÇÃO}

O implemento da tecnologia evolucionou a forma de relacionamento, a distância deixou de ser empecilho para que houvesse comunicação entre pessoas, principalmente a partir do advento das redes sociais, como corolário a informação e o conhecimento passaram a ser mais acessíveis.

O lado negativo desta evolução, é que o indivíduo passou a armazenar informações relativas a sua privacidade no mundo virtualizado, tornando-se cada vez mais vulnerável. Essas informações passaram a ser objeto de interesse do mercado econômico.

Nesse sentido, o presente trabalho visou abordar um dos temas que se tornou gritante no mundo digital, especialmente após a disseminação midiática de casos célebres que envolvem tratamento irregular dos dados pessoais.

A internet que deveria ser utilizada para benefício dos indivíduos passou a ser ambiente para cometimento de crimes cibernéticos e se valer como instrumento para violar direitos. Além disso, havia uma dificuldade da via legislativa em acompanhar o avanço tecnológico, implicando, por consequência, que a internet tornasse um lugar desconhecido. Onde não há lei não há ilegalidade. 


\section{A responsabilidade civil objetiva e o dano moral presumido em}

decorrência do tratamento indevido de dados

Direitos fundamentais e direitos da personalidade, sobretudo, privacidade e intimidade, tão valiosos, passaram a ser diretamente ofendidos.

As linhas que se seguem se dividem em três tópicos, o primeiro foi desenvolvido a base da pesquisa bibliográfica buscando ilustrar a sociedade da informação, expondo os elementos e a forma de funcionamento da quarta revolução industrial, além de exemplificar o tratamento irregular de dados com casos célebres.

O segundo abordará os direitos à privacidade, intimidade e sigilo de dados, utilizando-se do método argumentativo a base da pesquisa jurisprudencial e bibliográfica a fim de demonstrar que os dados compõem o direito fundamental da privacidade.

No terceiro analisa-se com base no método hermenêutico-jurídico a Lei Geral de Proteção de Dados, demonstrando que o tratamento irregular de dados pessoais pode ser lesivo aos direitos da personalidade de seu titular, e, em decorrência, traçando reflexões sobre a aplicação da responsabilidade civil objetiva assim como da configuração do dano moral presumido.

\section{A SOCIEDADE DA INFORMAÇÃO}

Sobre um aspecto sociológico a globalização e a tecnologia marcam o século XXI, alterando a forma das pessoas se relacionarem e fomentando a busca pela informação. Conforme ensina Eduardo Bittar sobre as relações atuais "[...] transmuta o foco das relações de comunicação inter praesentes para relações de comunicação inter absentes." (BITTAR, 2019, p. 831). Este prelúdio caracteriza a sociedade inserida na tecnologia, a denominada sociedade da informação.

O mundo pós-moderno possui como características a informação rápida, conhecimento nas palmas das mãos, globalização, tecnologia e internet. O sociólogo Zygmunt Bauman aponta que essa sociedade habita em um mundo líquido "[...] porque, como todos os líquidos, ele jamais se imobiliza nem conserva sua forma por muito tempo. Tudo ou quase tudo em nosso mundo está sempre em mudança." (BAUMAN, 2011, p. 7)

Esta mudança no modo de se relacionar foi diretamente influenciada pela internet, que é uma rede de extensão ilimitada, e redes, por sua vez, é algo que é responsável por interligar as coisas ou pessoas. 
A internet por ter uma extensão ilimitada traz diversas benesses aos usuários, contudo, traz malefícios, principalmente, em relação à privacidade. Em apertada síntese, cita-se Eduardo Bittar que elenca os pontos negativos, especificamente no que concerne à privacidade do sujeito de direito:

[...] (d) torna a privacidade e a informação as mercadorias de um tempo; [...] (f) cria a disputa, desestabilizadora de governos, pelos "pacotes de informações", um campo de guerra entre o "detentor da informação" e o "chantageado da era da informação"; (g) aumenta o grau de insegurança na administração, posse e circulação da informação, onde o roubo de dados, a hackerização de programas e a insegurança tecnológica aparecem como constantes ameaças; [...] (j) redefine a fronteira da privacidade, nos termos de novas aproximações de violações a direitos e liberdades; [...] (n) cria o tráfico de dados e informações, a cibercriminalidade com finalidades danosas, invasivas e delituosas, aí incluindo a extorsão pela posse de informações desvantajosas; [...] (BITTAR, 2018, p. 833, grifo nosso)

Percebe-se que esta mudança social de convivência para o mundo virtualizado fragiliza potencialmente a privacidade, uma vez que a inclusão digital exige informações pessoais dos usuários para utilização dos serviços ou aquisição de produtos, além de ser uma forma de vedar o anonimato.

Esse conjunto de informações sobre as pessoas são denominados de dados, que por sua vez são armazenados em uma base. Com o fito de diminuir a vulnerabilidade dos internautas, esta grande base de informações merece proteção dos tratadores.

Fato é, a internet se tornou algo indispensável no cotidiano das pessoas, não obstante, cogita-se elencar o livre acesso a internet no rol dos direitos fundamentais.

Entrementes, este ambiente cibernético deve ao menos oferecer mínima segurança aos usuários, sobretudo na proteção dos dados, pois neles estão contidas informações sobre a privacidade e intimidade dos sujeitos de direito.

Como bem lembra o jurista Stefano Rodotà, nas últimas décadas, vivenciamos um verdadeiro "processo de inexorável reinvenção da privacidade.” (RODOTÀ, 2008, p. 15). O fenômeno de virtualização das relações humanas parece que está no início, portanto, a proteção e a repressão ao tratamento indevido de dados devem ser aprofundadas.

\subsection{O tratamento de dados na quarta revolução industrial}


A quarta revolução industrial é responsável pela implementação tecnológica e virtualização das relações humanas, não obstante, o mundo vê surgir o fenômeno da digitalização, suas características consistem na onipresença de máquinas, computadores, notebooks, tablets e smartphones, livros digitais, conexão à internet e convergência da comunicação para o formato digital (Facebook, Instagram, Twitter, Telegram, Whatsapp, Microsoft Teams, Zoom).

Diante disso, os autores Hofmann e Rusch entendem que:

[...] a Quarta Revolução Industrial pode ser melhor descrita como uma mudança na lógica de fabricação para uma abordagem de valor cada vez mais descentralizada e auto-reguladora, habilitada por conceitos e tecnologias como CPS, IoT, IOS, computação em nuvem ou manufatura aditiva e fábricas inteligentes, de modo a ajudar as empresas a atender a produção futura requisitos. (HOFMANN; RUSCH, 2017, p. 25)

Nesse contexto, o mundo se prepara para uma nova geração de pessoas, os denominados nativos digitais, isto é, aqueles que nascem inseridos na tecnologia, de igual modo o mercado também se prepara para essas pessoas. São traçadas estratégias de marketing fundadas em análises de grandes bases de dados que contém informações sobre os consumidores.

É perceptível esta ingerência tecnológica nos modelos de negócios tradicionais, foram desenvolvidos novos, cita-se a Netflix na locação de filmes, a Uber no transporte urbano, o iFood no delivery, a Booking na hospedagem, os bancos e corretoras digitais no sistema financeiro, a Amazon no varejo, entre outros.

$\mathrm{Na}$ ciência jurídica, em específico no direito civil é fácil constatar esta mudança, o aumento exponencial de contratos entre ausentes (art. 434 do Código Civil) se dá em decorrência dos chamados contratos eletrônicos, os juristas Nelson Rosenvald e Cristiano Chaves de Farias, apontam que estes contratos sofrem o fenômeno da despersonalização, que dificulta a aferição de vício de consentimento do negócio jurídico, vejamos: “[...] no momento da celebração, em que são transmitidas as declarações de vontade, não estão presentes os seres humanos a quem são atribuíveis, mas sim computadores que se comunicam diretamente entre si." (ROSENVALD; FARIAS, 2017a, p. 364). Além deste elemento, tem-se a desmaterialização do contrato:

Ele é concluído sem forma física. São bits e códigos binários. Isto cria problemas quanto à prova da contratação, ou mesmo de seu conteúdo e momento. Muitas vezes, o próprio objeto do contrato é imaterial, assim o vício do objeto é informacional [...] Ademais, o comércio eletrônico atualiza 
a noção de objeto, pois as prestações contratuais dos contratos informáticos são imateriais, como o fornecimento de software, jogos, filmes e músicas. (ROSENVALD; FARIAS, 2017a, p. 365)

Neste ínterim, os crimes cibernéticos ganham espaço, há uma necessidade de readaptação na ótica da punibilidade, motivo pelo qual criou-se a Lei Carolina Dieckmann, com o fim de punir as invasões no espaço virtual. Isto porque, por trás desta indústria há um mercado lucrativo em relação aos roubos de dados.

A empresa Facebook S.A adota um programa chamado de bug bounty que recompensa monetariamente hackers por tentarem encontrar falhas na segurança do serviço prestado, encontrada as falhas blinda-se de outros invasores digitais, os chamados crackers. Nessa ambiência, obtempera Paulo de Almeida:

\begin{abstract}
A Indústria 4.0 necessita de proteção contra possíveis ataques de hackers, que podem comprometer o desempenho da empresa no que concerne à fabricação de produtos, além do risco de invasão e alteração/apropriação das informações sobre os clientes. (ALMEIDA, 2019, p. 66).
\end{abstract}

Dito isso, é preciso contextualizar e conceituar os elementos basilares e estruturantes desta nova realidade social. "São considerados elementos base para a Indústria 4.0 sistemas ciber físicos, internet das coisas (IoT) e internet de serviços (IoS).” (SACOMANO; et. al., 2018, p. 34), cujo a conceituação é a seguinte:

\begin{abstract}
- Os CPS são sistemas mecatrônicos compostos por sensores e atuadores, controlados por software que, monitorando uma série de dados, supervisionam e controlam processos industriais mecânicos, químicos, térmicos ou elétricos, no campo físico [...] Esses sistemas ciber físicos transmitem informações e dados em tempo real, conectados, por meio do espaço cibernético, mundo virtual para o mundo real.

- IoT [...] chamamos objetos inteligentes, ou smart products, quando a coisa, ou o objeto, passa a ter capacidade de processamento juntamente com a capacidade de conexão com a internet. [...] Geladeiras inteligentes poderão elaborar a lista dos itens faltantes, consultar mercados que tragam melhores relações custo-benefício, enviar a lista de compras já com os preços e condições de pagamento para a sua autorização, e uma vez autorizado, fechar o pedido de compra, para entrega no dia e horário da sua maior conveniência pessoal.

- Internet of services, ou abreviadamente IoS. Pela IoS, novos serviços são disponibilizados por meio da internet ou internamente à empresa. Você poderá ser alertado pelo celular/tablet ou computador que o seu carro precisa de revisão e/ou que chegou o período de trocar os pneus. (SACOMANO; et. al., 2018, p. 34-36, grifo nosso)
\end{abstract}

A tecnologia se manifesta nos produtos e serviços que são desenvolvidos com fulcro em uma base de dados que armazena os mais diversos perfis dos consumidores. 
Este método é utilizado para que haja um maior direcionamento dos produtos e serviços aumentando o consumo, evitando-se o desperdício.

Em relação aos elementos estruturantes, pode-se dizer que é neles que residem a maior preocupação quando se fala em danos causados em razão do tratamento irregular de dados, são eles:

- A Automação é definida como a realização de tarefas sem a intervenção humana, com equipamentos que funcionam sozinhos e possuem a capacidade de controlar a si próprios [...] O uso de robôs tem especial importância em tarefas que apresentam risco ao trabalhador, exigem grande velocidade e/ou precisão de execução, sejam atividades extenuantes ou repetitivas.

- Machine to Machine pode ser definido como a comunicação entre duas máquinas ou a transferência de dados de um dispositivo a um computador central que pode ser realizada por meio de rede com ou sem fio, por meio de cabos, bluetooth, rede de telefonia celular ou internet.

- Inteligência artificial é utilizar dispositivos ou métodos computacionais de forma similar à capacidade de raciocínio do ser humano, resolvendo problemas da maneira mais eficiente possível.

- Big data a massa de informações geradas por todo sistema, seja ele produtivo, comercial, marketing e outros, que precisa ser bem analisada, pois há riquezas de detalhes que podem significar o sucesso de qualquer empresa.

- Computação em nuvem assim chamada por não se saber onde estão localizados os servidores que armazenam e processam dados, assim como não se sabe por onde passam estes dados, nem onde os dados são replicados [...] A computação em nuvem é fundamental para que as informações e dados possam ser acessadas, de forma fácil, de qualquer parte do mundo em que haja internet.

- Segurança cibernética Como todas as informações, dados e comandos trafegam online, é importante que haja segurança contra invasões às redes de internet ou Intranet. $\mathrm{O}$ vazamento ou roubo dos dados e informações, ou a entrada de elementos maliciosos na rede, comprometem todo modelo da Indústria 4.0, sendo que ainda há muito a fazer para tornar a internet segura. (SACOMANO, et. al., 2018, p. 36-38)

Percebe-se que em todos os elementos estruturantes da indústria 4.0, tem-se o tratamento de dados, que pode ser conceituado pela Lei 13.709/2018 que dispõe sobre a Lei Geral de Proteção de Dados Pessoais como:

Art. $5^{\circ}$ Para os fins desta Lei, considera-se:

$\mathrm{X}$ - Tratamento: toda operação realizada com dados pessoais, como as que se referem a coleta, produção, recepção, classificação, utilização, acesso, reprodução, transmissão, distribuição, processamento, arquivamento, armazenamento, eliminação, avaliação ou controle da informação, modificação, comunicação, transferência, difusão ou extração; (BRASIL, 2018)

Trata-se de uma norma jurídica com várias condutas ou plurinucleares, e é daí que nasce a responsabilidade civil, como bem lembra José de Aguiar Dias: "toda 
manifestação da atividade humana traz em si o problema da responsabilidade." (DIAS, 1979, p. 1).

Dessa forma, qualquer conduta tipificada nesta norma jurídica que não observada, causará potencialmente um dano ao titular dos dados.

\title{
2.2 Casos célebres sobre o tratamento irregular de dados
}

Preliminarmente é imperioso destacar o conceito legal de dados, o artigo $5^{\circ}$ da Lei Geral de Proteção de Dados estabelece:

\begin{abstract}
Art. $5^{\circ}$ Para os fins desta Lei, considera-se:
I - dado pessoal: informação relacionada a pessoa natural identificada ou identificável;

II - dado pessoal sensível: dado pessoal sobre origem racial ou étnica, convicção religiosa, opinião política, filiação a sindicato ou a organização de caráter religioso, filosófico ou político, dado referente à saúde ou à vida sexual, dado genético ou biométrico, quando vinculado a uma pessoa natural; III - dado anonimizado: dado relativo a titular que não possa ser identificado, considerando a utilização de meios técnicos razoáveis e disponíveis na ocasião de seu tratamento; (BRASIL, 2018).
\end{abstract}

Desta leitura, conclui-se que os dados são ligados a privacidade, intimidade e ao sigilo, residem no âmbito dos direitos fundamentais e da personalidade. Ademais, quando alguém possui essas informações sobre a pessoa é possível traçar sua personalidade utilizando da inteligência artificial.

Em recente documentário postado no YouTube pela BBC News Brasil no ano de 2018, na eleição norte americana de 2016, houve o estouro na mídia do caso Facebook e Cambridge Analytica S.A, que em síntese, a empresa Cambridge Analytica S.A conseguiu acesso aos dados de cerca de 87 milhões de usuários do facebook, podendo filtrar com base em um algoritmo a personalidade de cada estadunidense. A empresa coletava as informações pessoais dos usuários e seu histórico de curtidas em páginas e publicações, e com esse arcabouço de informação, conseguia-se traçar o perfil eleitoral daquele cidadão.

Com esses dados em mãos, possibilitou-se, aos partidos que adquiriram essas informações, em tese, manipular as eleições, enviando anúncios direcionados as pessoas sobre as bandeiras defendidas por determinado candidato, e como já se sabia previamente a personalidade daquela pessoa, o anúncio direcionado era o que mais a agradava. (BBC, 25 de Abril, 2018). 
A inteligência artificial é um dos elementos estruturantes da indústria 4.0 e seu uso traz riscos, relembrando, é um software que tem capacidade de resolver problemas e por consequência substituir humanos.

No que diz respeito a substituição do ser humano não é algo distante, no âmbito do direito a inteligência artificial é uma realidade, tribunais como o STJ, STF e TJMG já adotam alguns softwares que ajudam na eficiência dos julgados, vejamos conforme foi noticiado pelo TJMG: “[...] sessão inédita da $8^{\text {a }}$ Câmara Cível do Tribunal de Justiça de Minas Gerais julgou, com apenas um click no computador, um total de 280 processos. Em menos de um segundo, todos os processos foram julgados." (TJMG, 2018).

De fato, pode ser um passo para o futuro com maior celeridade e eficiência nos julgados, em contrapartida terá uma menor sensibilidade dos julgadores na análise dos processos.

Muito embora a busca pela justiça numerária e automatizada seja tentadora, não se pode afastar a sensibilidade do judiciário. $O$ tato e a figura do magistrado são importantes no processo constitucional.

Há profissões que são insubstituíveis, em virtude do subjetivismo que o ser humano tem, como bem lembra o filósofo Thoms Nagel:

\footnotetext{
Até onde posso imaginar (e não consigo ir muito longe) isso me fornece dados apenas sobre o que poderia ser para mim comportar-me como um morcego se comporta. Mas esta não é a questão. Eu queria mesmo saber como é, para um morcego, ser um morcego. Mesmo se eu tentasse imaginar isso, estaria restrito às faculdades de minha própria mente, e estas são inadequadas para a tarefa. Eu não posso realizar a tarefa nem imaginando adições às minhas experiências atuais, nem graduais subtrações, nem imaginar eventuais combinações de adições, subtrações e modificações. (NAGEL, 1974, p. 109-115)
}

A metáfora que Nagel induz é que adquirimos conhecimento, através da experiência, um software de inteligência artificial jamais será como um humano, pois afinal, é um software.

Dessa forma, por mais que queiramos vivenciar as experiências de um morcego, jamais conseguiremos ser um ou sentir como um, pois não somos morcegos, estamos limitados a imaginação. Portanto, deve-se ter cautela ao delegar um ofício a uma inteligência artificial, pois um processo judicial necessita do tato e sensibilidade de um ser humano. 
Não obstante, sobre o uso da inteligência artificial tem-se o caso Vernon Prater e Brisha Borden, no qual buscava-se prever quem teria maior probabilidade de voltar a reincidir criminalmente. Vernon possuía um largo antecedente criminal de roubos a mão armada, enquanto Brisha, que é negra, possuía algumas contravenções penais consumadas na adolescência, quando submetidos ao programa de inteligência artificial, foi apontada que Brisha era cinco vezes mais perigosa que Vernon, fato é, que foi um algoritmo preconceituoso. (ANGWIN, 2019)

Outra situação gravíssima é em relação aos consumidores, que ao adentrarem em uma farmácia são seduzidos a descontos em troca de informar o CPF e outros dados pessoais, no ano de 2018 o Instituto de Referência em Internet e Sociedade submeteu ao Ministério Público de Minas Gerais uma representação para que fosse investigado qual seria a real finalidade no armazenamento dos dados dos consumidores. A rede farmacêutica Drogaria Araújo S.A negou-se a informar e recusou o termo de ajustamento da conduta, sendo multada pelo PROCON no montante de R\$ 7.930.801,72. (MPMG, 2018)

Duvida-se que esta prática muito comum nas farmácias tem finalidade diversa do desconto. Cogita-se que esses dados são vendidos às empresas de planos de saúde, pois, em tese, essas teriam acesso ao histórico de receituário daquele consumidor, sabendo qual a média anual que ele adoece, quais remédios consumiu e quais seus efeitos colaterais, podendo, com base em pesquisas saber qual o tempo estimado de vida daquela pessoa.

Pelo exposto, com o advento da Lei Geral de Proteção de Dados, espera-se que haja a efetiva proteção ao titular dos dados, bem como a devida reparação civil pelos danos causados em decorrência do tratamento indevido dessas informações.

\section{PRIVACIDADE: DIREITO A INTIMIDADE E AO SIGILO DOS DADOS}

O direito à privacidade é um direito fundamental tipificado na Constituição da República e também um direito da personalidade conforme hermenêutica civilista, é classificado no âmbito privado como um direito que está no rol dos direitos psíquicos, vejamos conforme a proposta de Carlos Alberto Bittar:

Por isso, podemos distribuir os direitos da personalidade em: a) direitos físicos; b) direitos psíquicos; c) direitos morais. Os primeiros são referentes a componentes materiais da estrutura humana (a integridade corporal, 
compreendendo: o corpo, como um todo; os órgãos; os membros; a imagem, ou efígie); os segundos, relativos a elementos intrínsecos à personalidade (integridade psíquica, compreendendo: a liberdade; a intimidade; o sigilo); e os últimos, respeitantes a atributos valorativos (ou virtudes) da pessoa na sociedade (o patrimônio moral, compreendendo: a identidade; a honra; as manifestações do intelecto). (BITTAR, 2015, p. 49, grifo nosso).

Sabendo que o direito à privacidade é um direito da personalidade, conclui-se que compõe aquilo que é essencial a pessoa e que qualquer violação afetará sua dignidade, pois afeta sua vida privada. Ademais, ensina Gilberto Jabur que: "O direito à vida privada posiciona-se como gênero ao qual pertencem o direito a intimidade e o direito ao segredo." (JABUR, 2000, p. 256).

Nesta linha de raciocínio, qualquer violação a esses direitos acarretará para o lesado a pretensão a reparação, seja a pessoa natural ou a pessoa jurídica, conquanto, a Lei Geral de Proteção de Dados serve a princípio, tão somente a pessoa humana conforme disposto no seu artigo $1^{\circ}$, e este diploma legal é norteado por alguns fundamentos, elencados no artigo $2^{\circ}$ vejamos: Art. $2^{\circ}$ A disciplina da proteção de dados pessoais tem como fundamentos: I - o respeito à privacidade; [...] IV - a inviolabilidade da intimidade, da honra e da imagem; (BRASIL, 2018)

Da leitura do dispositivo que regula os fundamentos da LGPD não é possível observar a tutela específica dos dados, isto porque, o sigilo aos dados está no interior do direito a intimidade, e que está no interior da privacidade, senão vejamos: "No campo do direito à intimidade são protegidos, dentre outros, os seguintes bens: confidências; informes de ordem pessoal (dados pessoais) [...].”(BITTAR, 2015, p. 173, grifo nosso).

Mesma conclusão que o Superior Tribunal Federal chegou ao julgar a medida cautelar proposta na ADI 6.387, que está pendente a publicação do Acórdão, nas linhas que se seguem a fundamentação ipsis litteris da eminente relatora Ministra Rosa Weber:

Tais informações, relacionadas à identificação - efetiva ou potencial - de pessoa natural, configuram dados pessoais e integram, nessa medida, o âmbito de proteção das cláusulas constitucionais assecuratórias da liberdade individual (art. $5^{\circ}$, caput), da privacidade e do livre desenvolvimento da personalidade (art. $5^{\circ}, \mathrm{X}$ e XII). Sua manipulação e tratamento, desse modo, hão de observar, sob pena de lesão a esses direitos, os limites delineados pela proteção constitucional.

(ADI 6387 MC-Ref, Relator(a): ROSA WEBER, Tribunal Pleno, julgado em 07/05/2020, PROCESSO ELETRÔNICO DJe-270, DIVULG 11-11-2020 PUBLIC 12-11-2020)

Pelo exposto, a Constituição da República de 1988 em seu artigo 5º inciso XII assegura de forma clara a privacidade e como corolário a proteção de dados. 
Importante ressaltar que é compreensível o que seria direito a privacidade, direito a intimidade e direito ao sigilo, mas a conceituação nem sempre é fácil, isto ocorre porque cada pessoa tem para si aquilo só a pertence e a mais ninguém.

Neste árduo trabalho de conceituar, os juristas Nelson Rosenvald e Cristiano Farias entendem que a privacidade:

[ ] é o refúgio impenetrável pela coletividade, merecendo proteção. Ou seja, é o direito de viver a sua própria vida em isolamento, não sendo submetido à publicidade que não provocou, nem desejou. Consiste no direito de obstar que a atividade de terceiro venha a conhecer, descobrir ou divulgar as particularidades de uma pessoa. (ROSENVALD; FARIAS, 2017b, p. 268).

Por sua vez, o direito a intimidade na perspectiva de Rui Stoco: "Será aquilo que não se quer compartilhar com ninguém mais, o direito de estar consigo mesmo." (STOCO, 2014, p. 2167).

$\mathrm{E}$ os dados encontram-se protegidos no direito à intimidade, que está abarcado pelo direito fundamental da privacidade, em contrapartida, o direito ao sigilo ou o direito ao segredo é um direito que nasce para o titular dos dados no momento em que ele abdica parcialmente do seu direito à privacidade, ou seja, quando são compartilhados com operadores, controladores ou provedores. Pode-se dizer, que o direito ao sigilo possui efeitos similares a uma obrigação propter rem, quem possui os dados é obrigado a mantê-lo em sigilo, sob pena de violar o direito do titular e proprietário dos dados.

Ademais, os responsáveis que possuem o dever ético e legal de não violarem o direito ao sigilo do titular dos dados, são denominados pela LGPD de controladores e operadores, senão vejamos:

Art. $5^{\circ}$ Para os fins desta Lei, considera-se:

VI - controlador: pessoa natural ou jurídica, de direito público ou privado, a quem competem as decisões referentes ao tratamento de dados pessoais; VII - operador: pessoa natural ou jurídica, de direito público ou privado, que realiza o tratamento de dados pessoais em nome do controlador; (BRASIL, 2018).

A todo momento as pessoas compartilham com os operadores e controladores informes pessoais para ter acesso a determinados sites ou então aplicativos, cria-se um nome, um login, um e-mail, uma senha, às vezes compartilha-se a localização, e todas essas informações são dados pessoais ou sensíveis do titular, que merecem a devida proteção para resguardar a privacidade e intimidade do usuário. 
Com fulcro no princípio da boa-fé objetiva do direito privado a LGPD em seu artigo $6^{\circ}$ elenca alguns princípios, sendo eles: finalidade, adequação, necessidade, livre acesso, qualidade dos dados, tratamento transparente, segurança, prevenção, não discriminação, responsabilização e prestação de contas.

Frisa-se, que nos ensinamentos de Manuel Atieza as diversas definições de norma jurídica, no atual sistema, mostram-se mais acertado compreendê-la como gênero do qual são espécies as regras e os princípios. (ATIENZA, 2014, p. 213)

Pelo exposto, havendo a violação de qualquer desses princípios ou então de qualquer outra conduta tipificada nesta lei, que viole a privacidade e intimidade do titular dos dados, configurará a ilicitude ou então o ato ilícito por equiparação, que são requisitos da responsabilidade civil.

Nota-se que se utiliza da locução ilicitude, por se tratar de responsabilidade objetiva, conforme será abordado no próximo tópico, nesse mesmo sentido, leciona Sergio Cavalieri Filho: "Não há que se falar em ato lícito se em todos os casos de responsabilidade objetiva há sempre a violação de um dever jurídico preexistente, o que configura a ilicitude.” (CAVALIERI FILHO, 2018, p. 20).

\section{RESPONSABILIDADE CIVIL PELO TRATAMENTO INDEVIDO DE DADOS}

Responsabilidade está intrinsecamente ligada ao dever de diligência, cautela e cuidado, e no âmbito jurídico pode-se dizer que é uma obrigação decorrente de uma violação, que poderá ser contratual ou extracontratual, motivo pelo qual a responsabilidade civil é considerada também uma fonte do direito obrigacional.

Entrelinhas, pode-se dizer que a responsabilidade civil é somente um substrato da responsabilidade jurídica, conceituada por Álvaro Villaça Azevedo como: “A responsabilidade civil nada mais é que o dever de indenizar o dano." (VILLAÇA, 2004, p. 276). Vai além disto, pois é a consequência da vida em sociedade, a responsabilidade é a dimensão de justiça existente no grupo social, que traduz na sua essência o não causar danos e sempre buscar repará-los quando causados.

A responsabilidade civil visa a mantença da ordem, com respaldo em dois deveres, "[...] um dever jurídico preexistente, de não lesar outrem, surgindo um outro posterior que é o de indenizar e recompor o equilíbrio social.” (CHADI, 2015, p. 425) 
Não é necessário discorrer sobre o aspecto histórico do instituto, nem mesmo criar conceitos novos, já que se alcançou sua excelência, contudo, não quer dizer que está por finalizada a possibilidade de novos avanços, por isso, deve-se atentar aos novos danos que decorre da violação do direito da privacidade, intimidade e sigilo, mediante inobservâncias no tratamento de dados.

Com efeito, o jurista Caio Mário da Silva Pereira ensina o motivo pelo qual, deve-se buscar progredir com o instituto da reparação civil: "A proteção à pessoa humana desempenha papel central.” (PEREIRA, 2018, p. 15).

\subsection{Responsabilidade civil contratual e extracontratual: tratamento dos dados}

A responsabilidade civil poderá ser contratual ou extracontratual, no que diz respeito a primeira, é importante aferir uma relação jurídica preliminar entre as partes, em que haverá a necessidade de dosar a culpa no inadimplemento contratual. Em relação a segunda, independe de relação jurídica preliminar entre as partes, e o inadimplemento dar-se-á quando o ofensor viola um dever jurídico de não lesar o outrem.

Impende salientar que há ainda uma terceira vertente do inadimplemento contratual, denominada de violação positiva do contrato, em suma, ocorre quando em uma relação contratual não há a observância dos deveres anexos da boa-fé objetiva, muito embora haja o cumprimento das cláusulas contratuais, a conduta tomada por uma parte perante a outra ofende a boa-fé objetiva, cita-se a omissão de informação quanto ao objeto do negócio jurídico. Ressalta-se que nesta modalidade de inadimplemento a culpa é presumida, portanto, a responsabilidade é objetiva, conforme estabelecido no enunciado 24 do Conselho Justiça Federal.

A conduta que causa a violação positiva do contrato advém de um abuso de direito estancada no artigo 187 do Código Civil, portanto, se uma pessoa tem o dever ético e legal de cumprir com os deveres anexos e toma uma conduta positiva ou omissiva a fim de não observá-los estará abusando do seu direito.

Dito isso, em relação ao tratamento de dados é possível a configuração da responsabilidade civil de forma contratual, cita-se por exemplo, quando o controlador contrata um operador para tratar dos dados, e este último não observa as cláusulas contratuais.

É possível falar em inadimplemento positivo do contrato no tratamento de dados, por exemplo, quando um consumidor realiza um contrato de compra e venda e informa seus 
dados a empresa em troca de desconto, mas esta última não informa a finalidade do armazenamento dos dados.

Por derradeiro, na maioria dos ilícitos praticados envolvendo o tratamento de dados o inadimplemento será extracontratual, cita-se a recente decisão do Egrégio TJMG sobre ataque cibernético:

\begin{abstract}
EMENTA: APELAÇÃO CÍVEL - AÇÃO DE INDENIZAÇÃO VIOLAÇÃO DE SIGILO DE DADOS POR ATAQUE CIBERNÉTICO DANO MORAL CONFIGURADO - REDUZIR VALOR DA INDENIZAÇÃO. - As consequências que decorreram da invasão dos dados cadastrais da autora por terceiros desautorizados, causaram abalos moral, passíveis de reparação. - Em acordo com as peculiaridades do caso, entendo que o valor da indenização fixada pelo juiz sentenciante deve ser reduzido, $\mathrm{O}$ que proporciona a reparação pecuniária do dano à ofendida e o efeito pedagógico ao ofensor, evitando-se a reiteração de condutas dessa natureza, sem que haja enriquecimento ilícito sem causa. (TJMG - Apelação Cível 1.0000.19.061299-4/001, Relator(a): Des.(a) Shirley Fenzi Bertão , $11^{\text {a }}$ CÂMARA CÍVEL, julgamento em 14/08/2019, publicação da súmula em 19/08/2019)
\end{abstract}

Curiosamente, os dados são bens incorpóreos e o mero tratamento não configura contrato de depósito, já que neste contrato o objeto deve ser móvel e material, assim por mais que o titular dos dados utilize de um serviço ou produto virtual que exija seus dados, não haverá nenhuma configuração contratual, mas mero efeitos de detenção, os operadores e controladores ao possuírem se obrigam a protegê-los. A detenção é uma posse que precede uma subordinação aos proprietários dos dados, contudo, não é cabível nenhuma ação possessória, já que há a incompatibilidade da apreensão material em bens imateriais.

\title{
4.2 Responsabilidade civil objetiva ou subjetiva
}

A responsabilidade civil possui pressupostos para sua configuração, conforme a teoria tetrapartida são eles: a) ato ilícito, b) culpa, c) nexo causal e d) dano, quando há a necessidade dos quatro pressupostos, estaremos diante da responsabilidade civil subjetiva elencada no artigo 186 do Código Civil, por outro lado, a responsabilidade civil objetiva está elencada no artigo 927 do Código Civil, e que "[...] sobejam banidos da obrigação de indenizar os pressupostos do ato ilícito e da culpa, concentrando-se a atenção do civilista nos pressupostos do risco da atividade, nexo causal e dano." (ROSENVALD; FARIAS; BRAGA NETTO, 2017c, p. 152). 
Quando se trata da responsabilidade civil da lei geral de proteção de dados, há uma controvérsia enorme, se será responsabilidade subjetiva ou objetiva, sendo que na verdade, pode-se afirmar com toda certeza que é objetiva. Para tanto, é preciso estudar o ponto nevrálgico da controvérsia, a culpa!

Buscando um conceito de culpa na perspectiva clássica da doutrina civilista Roberto Ruggiero preleciona:

Qualquer comportamento injusto, quer seja um fato positivo (comissão), quer negativo (omissão), quer um fato praticado com o deliberado propósito de prejudicar outrem ou de violar a esfera jurídica alheia, quer um fato praticado sem tal propósito e consistente numa diligência. (RUGGIERO, 1973, p. 388).

Se ainda existisse a culpa presumida, certamente na proteção dos dados teríamos a culpa in custodiando, todavia, o CC/02 baniu as presunções de culpa, mas esta foi uma ponte para se alcançar a teoria objetiva da responsabilidade.

Na responsabilidade civil objetiva, a culpa não é presumida, na verdade busca-se inverter o ônus da prova ao causador do dano e este último deverá provar que não agiu com culpa, pois é cediço que "a prova da culpa, em muitos casos, é verdadeiramente diabólica, erigindo-se em barreira intransponível para o lesado." (CAVALIERI FILHO, 2018, p. 57).

Logicamente, se não provada a culpa será presumida, bastando que haja prova do fato que levou ao evento danoso. E este fato poderá ter origem na violação de um dispositivo legal ou então no desenvolvimento de uma atividade que gera risco, conforme as teorias do risco.

O risco pode ser conceituado: "é probabilidade de dano, importando, isso, dizer que aquele que exercer uma atividade perigosa deve-lhe assumir os riscos e reparar o dano dela decorrente." (CAVALIERI FILHO, 2018, p. 225).

Além do mais, existe as espécies da teoria do risco, sendo elas: teoria do risco criado, teoria do risco administrativo, teoria do risco proveito, teoria do risco profissional e teoria do risco integral.

No que diz respeito a LGPD, terá relevância a teoria do risco proveito e do risco criado, porque a partir delas pode-se analisar a responsabilidade civil dos tratadores de dados. Da leitura do artigo $5^{\circ}, \mathrm{X}$ da LGPD, que refere ao tratamento de dados, trata-se de uma norma jurídica plurinuclear e nada obsta que determinada pessoa colete e utilize os dados e com eles ganhe proveito, imagine, o Facebook S.A que coleta e armazena os 
dados e com eles retira proveito direcionado anúncios publicitários aos usuários, neste caso, a teoria utilizada será do risco proveito.

Frisa-se que haverá responsabilidade pelo risco proveito, quando do tratamento de dados tira-se proveito, com efeito, quem deverá provar que não retira proveitos é o próprio causador do dano, conforme a teoria objetiva, onde há bônus haverá ônus.

Por outro lado, se a pessoa não retira proveito dos dados, poderá ser imputada pela teoria do risco criado, que nos ensinamentos de Eugênio Facchini Neto:

Dentro da teoria do risco criado, destarte, a responsabilidade não é mais a contrapartida do proveito ou lucro particular, mas sim a consequência inafastável da atividade em geral. [...] a qualquer ato do homem que seja potencialmente danoso a esfera jurídica de seus semelhantes. (NETO, 2007, p. 38).

Embora a pessoa física ou jurídica não tenha como objetivo finalístico o tratamento dos dados, mas pratica qualquer das condutas do artigo 5, $\mathrm{X}$ da LGPD para desenvolver sua atividade principal, estará criando um risco ao titular dos dados.

Não raro, é comum sociedades empresárias armazenarem dados do consumidor mesmo exercendo outra atividade empresarial, assim, em razão da atividade exercida, que não necessariamente precisa ser voltada a área da tecnologia, consuma qualquer das condutas referente ao tratamento de dados, estará criando um risco ao titular dos dados. Portanto, tratar da privacidade, intimidade e sigilo alheio em ambiente virtual, certamente gera riscos. Não obstante, obtempera os juristas Renato Blum e Marcos Gomes: "[...] para determinadas atividades nas quais se devem assumir riscos implícitos a ela, o que pode se aplicar à quase totalidade das relações jurídicas que envolvem o meio virtual, haverá responsabilidade independentemente de culpa.” (BLUM; GOMES, 2003, p. 213).

Nesse sentido é o que estabelece o artigo 42 da LGPD:

Art. 42. O controlador ou o operador que, em razão do exercício de atividade de tratamento de dados pessoais, causar a outrem dano patrimonial, moral, individual ou coletivo, em violação à legislação de proteção de dados pessoais, é obrigado a repará-lo. (BRASIL, 2018).

O diploma legal imputa ao controlador ou ao operador, que em razão de atividade de tratamento, e não em razão da atividade empresária (principal) exercida, portanto, uma não se confunde com a outra. 
Com efeito, quando se fala em risco a palavra antônimo é segurança, e de forma incisiva a LGPD estabelece no artigo 44, parágrafo único a seguinte redação: “Art. 44 [...] Parágrafo único. Responde pelos danos decorrentes da violação da segurança dos dados o controlador ou o operador que, ao deixar de adotar as medidas de segurança previstas no art. 46 desta Lei, der causa ao dano.” (BRASIL, 2018). Nesta esteira, também haverá violação, quando o tratador dos dados não adota medidas de segurança para manutenção do sigilo da privacidade alheia.

\subsection{Dano moral in re ipsa}

A responsabilidade civil pressupõe um dano, por isso "[...] falar em dano significa darlhe um sentido sempre ligado a ideia de prejuízo ou perda." (STOCO, 2014, p. 1661). Preliminarmente, é preciso considerar qual o bem jurídico tutelado pela Lei Geral de Proteção de Dados e indubitavelmente são os direitos da privacidade, intimidade e sigilo de dados do sujeito de direito.

Pelo exposto, sabendo que o tratamento de dados poderá lesar direitos da personalidade, surge o dano moral, que é compreendido como uma espécie de danos extrapatrimoniais:

\footnotetext{
Dano moral não mais se restringe à dor, tristeza e sofrimento, estendendo a sua tutela a todos os bens personalíssimos - os complexos de ordem ética -, razão pela qual podemos defini-lo, de forma abrangente, como sendo uma agressão a um bem ou atributo da personalidade. (CAVALIERI FILHO, 2018, p. 118, grifo do autor)
}

Por muito tempo assimilou-se o dano moral ao aborrecimento, estresse, dor, mal sentimento, contudo, isso são sentimentos, ou seja, são os efeitos de um dano. O dano já foi causado, e ele poderá ou não gerar sentimentos, não pode-se estudar os institutos pelos seus efeitos, os tribunais não podem julgar com base no sentimento do lesado, por isso o dano moral deve ser entendido como violação aos direitos da personalidade, que eventualmente, poderá, mas não necessariamente, ter como efeito o aborrecimento, o dissabor, entre outros sentimentos. O bem jurídico a ser reparado são os direitos da personalidade e não o que a pessoa sentiu.

Em relação ao dano moral in re ipsa, tende-se a sedimentar que qualquer dano a direitos fundamentais ou da personalidade será presumido pelos próprios fatos, cita-se a conceituação dada pelo jurista Paulo Lobo: 
De modo mais amplo, os direitos da personalidade oferecem um conjunto de situações definidas pelo sistema jurídico, inerentes à pessoa, cuja lesão faz incidir diretamente a pretensão aos danos morais, de modo objetivo e controlável, não sendo necessária a prova do prejuízo ou recurso à existência de dor moral ou psíquica, sofrimentos ou incômodos. A responsabilidade opera-se pelo simples fato da violação (damnu in re ipsa); assim, verificada lesão a direitos da personalidade, surge a necessidade de reparação do dano moral. (LÔBO, 2019, p. 349, grifo nosso).

Sabendo então que os dados estão abarcados pelo direito da privacidade, que por sua vez é um direito fundamental e da personalidade, qualquer tratamento indevido subsistirá para o lesado o dano moral em sua modalidade in re ipsa.

O Superior Tribunal de Justiça já vem adotando que qualquer violação a dignidade acarretará o dano in re ipsa, senão vejamos conforme informativo 513.

\begin{abstract}
DIREITO CIVIL. DANO MORAL. OFENSA À DIGNIDADE DA PESSOA HUMANA. DANO IN RE IPSA. Sempre que demonstrada a ocorrência de ofensa injusta à dignidade da pessoa humana, dispensa-se a comprovação de dor e sofrimento para configuração de dano moral. Segundo doutrina e jurisprudência do STJ, onde se vislumbra a violação de um direito fundamental, assim eleito pela $\mathrm{CF}$, também se alcançará, por consequência, uma inevitável violação da dignidade do ser humano. A compensação nesse caso independe da demonstração da dor, traduzindo-se, pois, em consequência in re ipsa, intrínseca à própria conduta que injustamente atinja a dignidade do ser humano. Aliás, cumpre ressaltar que essas sensações (dor e sofrimento), que costumeiramente estão atreladas à experiência das vítimas de danos morais, não se traduzem no próprio dano, mas têm nele sua causa direta. REsp 1.292.141-SP, Rel. Min. Nancy Andrighi, julgado em 4/12/2012.
\end{abstract}

Recentemente a Augusta Corte de Cidadania em seu informativo jurisprudencial 660 que julgou o Resp. 1.758.799/MG, destacou que:

CONFIGURA DANO MORAL IN RE IPSA a ausência de comunicação acerca da disponibilização/comercialização de informações pessoais em bancos de dados do consumidor.” (REsp 1.758.799-MG, Rel. Min. Nancy Andrighi, Terceira Turma, por unanimidade, julgado em 12/11/2019, DJe 19/11/2019)

Dessa forma, por mais que o julgado trate sobre a comercialização ou disponibilização de dados, seu objeto é resguardar a privacidade do sujeito de direito, portanto, o tratamento indevido dos dados ou a não observância da mantença de medidas de segurança com fito de resguardar o sigilo dos dados, lesiona direitos da personalidade acarretando então o dano moral presumido.

\title{
5 CONSIDERAÇÕES FINAIS
}


Por tudo que foi exposto, pode-se concluir que na sociedade da informação há uma premente necessidade de promover a proteção da privacidade dos usuários, isto porque, a todo instante as pessoas compartilham informações e dados pessoais em sites e aplicativos.

Nesta ambiência, o direito é uma mutante que se adapta ao tempo que vige e, na sociedade da informação é imprescindível que ele proteja aquilo que é imanente ao ser humano, sua privacidade e intimidade, e reprimir quando violadas senão seu titular ficará desamparado.

Dessa forma, sabendo que os dados são intrínsecos ao direito fundamental da intimidade, pode-se concluir que o compartilhamento dos mesmos com os operadores e controladores faz nascer para estes o dever de manter em sigilo dessas informações, bem como adotar boas medidas a fim de resguardá-los de terceiros invasores.

Além disto, conforme sustentado, o tratamento de dados consiste em uma norma jurídica plurinuclear e, certamente, tratar da privacidade alheia é um risco, ainda mais em ambiente virtual, motivo pelo qual, fala-se em responsabilidade objetiva.

Havendo o tratamento indevido dos dados nada impede que seja adotada a teoria do risco proveito, quando os tratadores de dados tiram proveito do uso dos dados, ou então seja adotada a teoria do risco criado quando não se retira proveito do tratamento dos dados, por exemplo, só há o armazenamento.

Ao se verificar a responsabilidade, surge o questionamento, o dano. Que poderá ser causado por inadimplemento contratual, extracontratual e pela violação positiva do contrato.

Havendo o tratamento indevido dos dados, subsistirá para o titular dos dados o manejo da ação indenizatória por dano moral, que será em sua modalidade in re ipsa, uma vez que tanto a doutrina quanto os tribunais sedimentaram que havendo violação de direitos fundamentais e da personalidade o dano moral é presumido, não sendo necessária sua prova. 


\section{REFERÊNCIAS}

ALMEIDA, Paulo Samuel de. Indústria 4.0: princípios básicos, aplicabilidade e implantação na área industrial. São Paulo: Érica, 2019.

ANGWIN, Julia. LARSON, Jeff. MATTU, Surya. KIRCHNER, Lauren. Machine

Bias. Disponível em: < https://www.propublica.org/article/machine-bias-riskassessments-in-criminal-sentencing >. Acesso em 28 de ago. de 2020.

ATIENZA, Manuel. As razões do direito: teorias da argumentação jurídica. Tradução de Maria Cristina Guimarães Cupertino. 2. ed. Rio de Janeiro: Forense, 2014. AZEVEDO, Álvaro Villaça. Teoria Geral das Obrigações. Responsabilidade Civil. 10. ed. São Paulo: Atlas, 2004.

BAUMAN, Zygmunt. 44 cartas do mundo líquido moderno. Rio de Janeiro: Zahar, 2011.

BBC News Brasil. Como a Cambridge Analytica analisou a personalidade de milhões de usuários no Facebook. 25 de Abril de 2018. 1 vídeo (4 min. 13s). Publicado por BBC News Brasil. Disponível em: <https://www.youtube.com/watch?v=x1SnHHby0wA >. Acesso em 28 de ago. de 2020.

BITTAR, Carlos Alberto. Os direitos da personalidade. 8. ed. rev. aum. e mod. por Eduardo C. B. Bittar. São Paulo: Saraiva, 2015.

BITTAR, Eduardo C. B. Curso de filosofia do direito. 14. ed. Rio de Janeiro: Atlas, 2019.

BLUM, Renato Opice; BRUNO, Marcos Gomes. O novo Código Civil e o direito eletrônico. In: DELGADO, Mário Luiz; ALVES, Jones Figueirêdo (Coord.). Questões controvertidas no novo Código Civil. São Paulo: Método, 2003.

BRASIL. Constituição da República Federativa do Brasil de 1988. Brasília, DF: Presidência da República, [2016]. Disponível em: http://www.planalto.gov.br/ccivil_03/Constituicao/CConstituiçao.htm. Acesso em: 29 ago. 2020.

BRASIL. Lei no 13.709, de 14 de agosto de 2018. Lei Geral de Proteção de Dados Pessoais. Brasília. Disponível em: < http://www.planalto.gov.br/ccivil_03/_ato20152018/2018/lei/L13709.htm >. Acesso em: 29 ago. 2020. 
CAVAlIERI FILHO, Sérgio. Programa de responsabilidade civil. 13. ed. Rio de Janeiro: Atlas, 2018.

CHADI, Ricardo. Indenização por perda de uma chance e sua adequada fundamentação. In: GUERRA, Ricardo; DINIZ, Giovanni Antonio, CHADI, Ricardo (org). Direito do Trabalho. 1. ed. Carderno 2. Belo Horizonte: Fumarc: 2015.

DIAS, José de Aguiar. Da responsabilidade Civil. 6. ed. v.1, Rio de Janeiro: Forense, 1979.

MPMG. Drogaria Araújo deverá pagar multa de $\mathrm{R} \$ 7$ milhões por capturar $\mathrm{CPF}$ dos consumidores. Belo Horizonte, 2018. Disponível em: < https://www.mpmg.mp.br/comunicacao/noticias/drogaria-araujo-devera-pagar-multade-r-7-milhoes-por-capturar-cpf-dos-consumidores.htm >. Acesso em: 28 ago. 2020. NAGEL, Thoms. Como é ser um morcego? (1974). Revista Abordagem Gestalt. Goiânia, v. 19, n. 1, p.109-115, jul. 2013 . Disponível em < http://pepsic.bvsalud.org/scielo.php?script=sci_arttext\&pid=S180968672013000100014\&lng=pt\&nrm=iso >. Acesso em: 07 fev. 2021.

NETO, Eugenio Facchini. Da responsabilidade civil no novo Código. Revista Jurídica Porto Alegre: Notadez. Ano 55, junho, nº 356, p. 38, 2007.

HOFMANN, E.; RÜSCH, M. Industry 4.0 and the current status as well as future prospects on logistics. Computers in Industry, v. 89, p. 23-34, 2017.

JABUR, Gilberto Haddad. Liberdade de pensamento e direito à vida privada: conflitos entre direitos da personalidade. São Paulo: Revista dos Tribunais, 2000.

LÔBO, Paulo. Direito Civil: obrigações. 7. ed. v.2. São Paulo: Saraiva Educação, 2019.

PEREIRA, Caio Mário da Silva. Responsabilidade Civil. Atual. Gustavo Tepedino. 12. ed. rev., atual. e ampl Rio de Janeiro: Forense, 2018.

RODOTÀ, Stefano. A vida na sociedade da vigilância: a privacidade hoje. Rio de Janeiro: Renovar, 2008.

ROSEnVALD, Nelson; FARIAS, Cristiano Chaves de. Curso de Direito Civil: contratos. 7. ed. rev. atual. Salvador: JusPodivm, 2017a.

ROSENVALD, Nelson; FARIAS, Cristiano Chaves de. Curso de Direito Civil: parte geral e LINDB. 15. Ed. rev., ampl. e atual. Salvador: JusPodivm, 2017 b.

ROSENVALD, Nelson; FARIAS, Cristiano Chaves de; BRAGA NETTO, Felipe Peixoto. Responsabilidade Civil. 4. ed. rev. atual. Salvador: Juspodivm, 2017c. 
RUGGIERO, Roberto. Instituições de direito civil. Trad. de Ary dos Santos, Antônio Chaves e Fábio Maria de Mattia. 3. ed. v.3. São Paulo: Saraiva, 1973.

SACOMANO, Jose Benedito; et. al. Indústria 4.0: conceitos e fundamentos. São Paulo: Blucher, 2018.

STOCO, Rui. Tratado de Responsabilidade Civil: doutrina e jurisprudência. 10. ed. rev. atual. e reform. São Paulo: Revista dos Tribunais, 2014.

STF, ADI 6387 MC-Ref, Relator(a): ROSA WEBER, Tribunal Pleno, julgado em 07/05/2020. Disponível em https://jurisprudencia.stf.jus.br/pages/search/sjur436273/false > Acesso em 06 de jan de 2021.

STJ- Informativo no 0513. Período: 6 de março de 2013. $3^{\text {a }}$ Turma-REsp 1.292.141-SP. Rel Min. Nancy Andrighi. Disponível em: < https://scon.stj.jus.br/SCON/SearchBRS?b=INFJ\&tipo=informativo\&livre= $@ \mathrm{COD}=\% 2$ $70513 \% 27$ > Acesso em: 04 set 2020.

STJ- Informativo no 660. Período: 6 de dezembro de 2010. REsp. 1.758.799/MG. Rel. Min. Nancy Andrighi. Disponível em https://www.stj.jus.br/publicacaoinstitucional/index.php/informjurisdata/article/view/38 66/4092 >. Acesso em: 04 de jan de 2021.

TJMG, TJMG utiliza inteligência artificial em julgamento virtual. Notícia. 2018. Disponível em: < https://www.tjmg.jus.br/portal-tjmg/noticias/tjmg-utiliza-inteligenciaartificial-em-julgamento-virtual.htm\#.X0kNctRKjIU >. Acesso em 28 ago. 2020. 